\title{
Só os militantes suportam lidar com a loucura? A Reforma Psiquiátrica em questão a partir de seus trabalhadores
}

RAMMINGER, Tatiana.

Trabalhadores em Saúde Mental: reforma psiquiátrica, saúde do trabalhador e modos de subjetivação nos serviços de saúde mental. Santa Cruz do Sul: EDUNISC, 2006. 104p.

| 1 Martinho Braga Batista e Silva |

${ }^{1}$ Doutorando em Antropologia Social, pelo Programa de Pós-Graduação em Antropologia Social (PPGAS/Museu Nacional), Universidade Federal do Rio de Janeiro. Endereço eletrônico: martinho02003@yahoo.com.br.

Elaborado a partir de uma dissertação de mestrado em Psicologia Social defendida na Universidade Federal do Rio Grande do Sul (UFRGS), o livro aponta densos elementos teóricos e metodológicos para pensar as políticas de saúde mental e de saúde do trabalhador no contexto da implantação do Sistema Único de Saúde (SUS). Analisa documentos governamentais e entrevistas de profissionais com base em uma parcela singular do referencial analítico foucaultiano, posterior aos textos clássicos sobre a história da loucura e o poder disciplinar: os jogos de verdade e os modos de subjetivação.

Além disso, o que por si só favorece um olhar atento - ou pelo menos curioso - sobre o debate acerca da gestão e formação de recursos humanos para o campo da Saúde Mental, o foco da sua pesquisa são os trabalhadores, esse contingente cada vez maior de enfermeiros, psicólogos, psiquiatras, terapeutas ocupacionais e assistentes sociais - entre outros, evidentemente - que se ocupam de uma tarefa nada modesta: cuidar dos portadores de transtorno mental, sem com isso excluí-los da sociedade. Em torno da saúde desses "funcionários-militantespacientes" - em sua maior parte mulheres, como nota a autora - são tecidos discursos, tais como a Medicina do Trabalho, atualizado na perícia médica. 
Entretanto, também são desencadeados processos de resistência, vinculando subjetividade e trabalho na abordagem da Saúde do Trabalhador de Saúde Mental, instigando uma prática reflexiva.

O livro está dividido em quatro partes. Em "Uma curiosidade, uma escolha, um conceito", a autora apresenta as motivações da pesquisa, extraídas de sua atuação junto à gestão de recursos humanos no contexto da Reforma Psiquiátrica, assim como as opções teóricas e metodológicas, foucaultianas por sinal, tais como a ferramenta genealogia e o conceito subjetividade. Em "Jogos de Verdade", essa psicóloga conduz uma genealogia do trabalho e das políticas de saúde mental, mostrando a constituição tanto do saber-poder hegemônico da Medicina do Trabalho, da Psiquiatria e da Saúde Pública, quanto dos discursos engendrados como alternativas ao mesmo, a Saúde do Trabalhador, a Saúde Mental e a Saúde Coletiva. Em "Experiência de Si", essa militante do movimento pela Reforma Psiquiátrica nos coloca em contato com os modos de subjetivação em serviços de saúde mental, ou seja, com aquilo que os próprios trabalhadores apontam como modos de lidar consigo em meio às demandas institucionais, a forma pela qual se constituem enquanto sujeitos em meio aos discursos religioso, científico e militante. Enfim, em "Loucas Trajetórias", a autora-gestora-psicólogapesquisadora-militante retoma o fio da pesquisa, qual seja, seu percurso profissional e a questão - que remete a muitas outras trajetórias - do modo de subjetivação militante no campo da Saúde Mental.

A primeira parte é uma contribuição contextualizada e localizada ao movimento pela Reforma Psiquiátrica no país, apontando para a importância de nossas implicações nesse processo serem colocadas em análise. A autora não só indica o lócus de seu trabalho, a equipe da Coordenação de Saúde Mental do Estado do Rio Grande do Sul, como também o lugar de onde fala, qual seja, gestora; não só explicita o teor intersetorial e articulado aos movimentos sociais que essa política regional pautada na atenção integral alcançou - vide o espaço que o Fórum Gaúcho tem assumido na defesa do projeto reformista -, como também os impasses que ultrapassam, em grande parte, a vontade política e os recursos financeiros, tais como o investimento dos servidores públicos no próprio trabalho.

Daí as perguntas-chave da sua pesquisa - "Um processo de desinstitucionalização só é possível com trabalhadores-militantes?” (p. 13) - justificando a flexibilização para contratação de trabalhadores mais sensibilizados e identificados com as 
propostas reformistas. A "capacitação e a formação dos trabalhadores bastam para avançar no processo de desinstitucionalização da loucura?” (p. 14), prescindindo do compromisso de criar espaços de reflexão sobre o trabalho, construindo coletivamente um novo saber, considerando também as experiências dos trabalhadores. Não é preciso dizer o quanto essas questôes ultrapassam em muito o âmbito das políticas públicas de saúde mental, já que também se colocam, pelo menos, no que tange à viabilização de agentes comunitários de saúde e médicos ao longo da implantação do Programa de Saúde da Família.

$\mathrm{Na}$ segunda parte, retira as consequiências da escolha da genealogia como ferramenta de pesquisa, incluindo na análise das relaçôes de poder no trabalho um dos suportes da atuação dos gestores na formulação de políticas públicas: os documentos governamentais, atravessados por discursos que engendram regimes de verdade.

Primeiro, através de uma bibliografia consistente e atual sobre a Reforma Sanitária e a Reforma Psiquiátrica, constrói pares de oposiçôes no sentido de dar relevo às lutas e conflitos para impor uma dada concepção do processo saúdedoença como universal: "Saúde Coletiva x Saúde Pública", por um lado, "Saúde Mental x Psiquiatria”, por outro. Assim, o discurso da Saúde Coletiva permitiria abordar as dimensões simbólica, ética e política do processo saúde-doença, para além do registro biológico, assim como possibilitaria incluir os trabalhadores e a sociedade civil no circuito de decisões sobre as políticas públicas de saúde, fortalecendo a transdisciplinaridade e a participação social. Já o discurso da Saúde Mental, assentado na consideração de que a experiência da loucura enquanto doença mental é uma verdade construída historicamente, aponta para a implicação de toda a sociedade no questionamento da segregação da loucura. Esse recurso epistemológico e metodológico situa o saber psiquiátrico como "mais um", e não "o" discurso: entre esse "discurso científico", pautado pela idéia de cura da doença mental, e um "discurso religioso", guiado pela expectativa de salvação espiritual, constitui-se um "discurso da Reforma Psiquiátrica", convocando o trabalhador a implicar-se política e afetivamente com a construção de um outro modo de cuidar e entender a loucura.

Em seguida, com base em variados relatórios de conferências nacionais de saúde no âmbito do SUS, destaca a presença de recomendaçōes sobre o tema Saúde do Trabalhador nas conferências de Saúde Mental, assim como aquelas acerca do assunto 
Saúde Mental nas conferências de Saúde do Trabalhador. A autora lança mão de uma tríade, mais do que das dicotomias anteriores, para reunir mais elementos dessa rede discursiva com efeitos sobre o trabalho e os trabalhadores de saúde mental: "Medicina do Trabalho - Saúde Ocupacional - Saúde do Trabalhador". Mas essa tríade é atravessada por outro par em conflito, "Público x Privado", "Capital x Trabalho". Assim, a Medicina do Trabalho é apresentada como "braço do empresário" (p. 48) para a recuperação do trabalhador, visando a seu conserto e retorno à linha de produção: o aspecto central é a capacidade ou não de produzir. A Saúde Ocupacional refere-se à "passagem da unicausalidade para a multicausalidade na explicação etiológica das doenças, e de um modelo exclusivamente médico para um modelo multiprofissional” (p. 49). Já na rede enunciativa da Saúde do Trabalhador, assim como no campo da Saúde Coletiva, há uma valorização do protagonismo dos trabalhadores e movimentos populares. Entretanto, no contexto histórico pós-1980, as "políticas públicas direcionadas à saúde do trabalhador elegeram como foco principal os trabalhadores vinculados às organizaçóes privadas, deixando uma importante lacuna na atenção em saúde para os servidores públicos e mais ainda para os trabalhadores da saúde" (p. 51).

O assunto Saúde do Trabalhador não aparece na I Conferência Nacional de Saúde Mental (1987), mas apenas na II (1992) e III Conferências (2001); na II Conferência apontam-se recomendaçóes para os trabalhadores de um modo geral, seja de serviços públicos ou privados, seja ou não da saúde. Na III Conferência é que o tema da Saúde Mental do Trabalhador de Saúde emerge de modo inequívoco, indicando a necessidade de superar formas verticalizadas de gestão, assim como de instalar a supervisão institucional nos serviços.

Já o assunto Saúde Mental aparece nas duas Conferências Nacionais de Saúde do Trabalhador, em 1986 e 1994. Na I Conferência, a discussão sobre a saúde mental do trabalhador é considerada incipiente pela autora, apesar de ela sublinhar o relevo que os sindicatos e associações de classe ganharam em relação ao empresariado. Na II Conferência, com uma presença maior de atores sociais ligados às universidades, dedicase atenção ao sofrimento do trabalhador, mais do que à capacidade de produção. Além disso, são enfatizados o controle sobre o processo produtivo e o conhecimento dos trabalhadores no delineamento de estratégias de ação.

A configuração de uma abordagem da Saúde do Trabalhador em Saúde Mental, segundo a autora, tem sido demarcada por dois pólos antagônicos: um centrado 
na motivação e satisfação no trabalho, nas patologias do indivíduo sem relação necessária com o trabalho; outro centrado no trabalho como fator constitutivo de adoecimento e saúde mental. Esse antagonismo se dispersa em quatro correntes de pensamento: pesquisas de base epidemiológica e/ou diagnóstica; teorias sobre o estresse; psicodinâmica do trabalho; estudos de subjetividade e trabalho. A autora procura embasar sua leitura das entrevistas de trabalhadores de saúde mental nesta última linha de pensamento, já que subjetividade seria um conceito capaz de afirmar a indissociabilidade entre o individual e o coletivo, rompendo com as dicotomias que tradicionalmente marcaram o campo da Saúde Mental e Trabalho. $\mathrm{Na}$ terceira parte, essa perspectiva nos lança em direção à maneira pela qual o sujeito faz a experiência de si mesmo em um jogo de verdade, reconhecendo a si mesmo como trabalhador de saúde mental.

Desta maneira, na terceira parte a autora desloca o foco dos papéis para as pessoas, dos documentos governamentais para as entrevistas com profissionais, da genealogia como ferramenta para a subjetividade como conceito: partindo dos regimes de verdade, embarca nos modos de subjetivação dos trabalhadores de saúde mental. Nesse momento crucial do livro, a autora se ocupa da experiência de si dos trabalhadores em meio à rede enunciativa presente nos textos de sustentação das políticas de saúde mental e saúde do trabalhador. Escuta tanto os peritos que atendem a servidores públicos, quanto os servidores públicos que atendem aos portadores de transtorno mental, por meio de entrevistas individuais, observação de eventos de reivindicação coletiva pública e questionários difundidos por internet.

Centrados na lógica da Medicina do Trabalho, os peritos médicos não vêem relação entre adoecimento e atividades de trabalho, constatando que a maioria dos casos que procuram o Departamento de Perícia Médica o faz por apresentar "problemas individuais". Os servidores públicos não costumam procurar os Centros de Referência do Trabalhador, mas o atendimento em saúde privado via convênio (p. 63). Inclusive, embora outro departamento com equipe de saúde mental problematize esse mandato de avaliação diagnóstica e homologação de licençassaúde, ao identificar algum grau de adoecimento costuma encaminhar os servidores que os procuram para tratamento individual em instituição privada. Além disso, percebem resistência dos trabalhadores da área da saúde a buscarem ajuda, em função do preconceito: como se ele não pudesse adoecer, sob pena de ter sua condição de trabalhador questionada. 
Os trabalhadores de um dos Centros de Atenção Psicossocial (CAPS) do município de Porto Alegre entrevistados são em número de 27, sendo que oferecem um conjunto diversificado de recursos terapêuticos para os mais de 200 portadores de transtorno mental matriculados, incluindo atendimento a moradores de rua e acompanhamento terapêutico. Os demais trabalhadores entrevistados são em número de 18, compondo um grupo heterogêneo (um deles, por exemplo, trabalha em hospital geral, mas nenhum deles em hospital psiquiátrico), no qual a maioria trabalha na gestão municipal ou estadual de saúde mental e realizou alguma pósgraduação. Entretanto, em ambas as amostras a maioria dos trabalhadores é do sexo feminino. Além disso, a autora nota que todos estão atravessados pela mesma rede enunciativa, o que justificou a integração das entrevistas.

Os relatos dos trabalhadores nos remetem ao cotidiano da atenção psicossocial, vivenciado por eles de modo aparentemente ambíguo: com margem de liberdade para que cada local defina seus modos de trabalhar, bem distante, portanto, da organização de trabalho vertical e burocrática; com um conjunto amplo e expressivo de demandas no cotidiano, próximo do desgaste e da sobrecarga. Aparentemente porque apontam para uma questão comum: a falta de políticas públicas de atenção à saúde do servidor público, imerso em cobranças de diferente ordem, embora, no caso dos trabalhadores de saúde mental, nem tanto assim controlados pela produção.

Segundo a autora, "foram identificadas poucas ações de cuidado com os cuidadores nos serviços de saúde mental, entre elas: exercícios de saúde laboral; capacitações; reuniōes de equipe; redução da jornada de trabalho; e a supervisão" (p. 73), sendo que "a falta de integração da equipe e de espaços de escuta e reflexão são identificados como fatores que contribuem para o adoecimento dos trabalhadores" (p. 74). Esse contexto favorece justamente a busca de soluçôes individuais, como a busca de supervisão fora dos serviços públicos e o desabafo entre duplas de colegas de equipe. Mas esses desafios em serviços que carecem de recursos e não têm regras prontas são contornados, apontando para algo além da sobrecarga: uma saúde possível no trabalho, a possibilidade de inventar o próprio trabalho, algum espaço de criação e autoria frente às demandas institucionais.

Esses trabalhadores implicados, desgastados e disponíveis para a mudança e a criação, são aqueles que, em outro cenário - o da luta pela manutenção do discurso da Reforma Psiquiátrica nas políticas pública de saúde mental -, sentem-se fragilizados diante da possibilidade de retomada do discurso médico-psiquiátrico. 
Há uma tensão entre trabalhadores acostumados com uma organização do processo de trabalho mais hierarquizada, própria do hospital, e aqueles que batalham por modos de trabalho mais horizontalizados, fazendo com que algumas pessoas adoeçam por não "encaixar-se" ao serviço, ou "não consigam ficar". Esse contexto permite à autora retomar uma de suas questôes iniciais: seria a Reforma Psiquiátrica possível apenas com militantes? Mais do que isso, como esse regime de verdade acolhe trabalhadores formados prioritariamente fora desse campo, sem a disponibilidade de implicação que a Reforma exige?

Enfim, na quarta e última parte de seu livro, a autora explicita um quadro do processo de Reforma Psiquiátrica brasileira no qual o "desgaste", a "sobrecarga" e a "militância" se aproximam e distanciam dependendo da posição que ocuparmos ao acompanhar seu argumento. Em meio a esse conjunto de forças em conflito, no interior das quais estão imersos gestores, pesquisadores, sindicalistas, peritos, cuidadores e, mais, gestores que viram pesquisadores e funcionários públicos que se tornam pacientes, a abordagem foucaultiana das práticas discursivas ganha relevo. No entanto, as potencialidades e, por que não, as limitaçôes da perspectiva teórica e metodológica adotada pela autora também são exibidos. Fica claro, quando retomamos as duas questôes-chave do livro, relativas à militância e à capacitação de recursos humanos, sua resposta: há necessidade de uma prática reflexiva, com o protagonismo dos trabalhadores, assim como um espaço para a problematização do trabalho, da saúde e das relações de poder/saber (p. 60-61). Também fica bastante visível o problema do modo de subjetivação militante no campo da Saúde Mental, na medida em que a Reforma Psiquiátrica se torna uma imposição, algo que "tem que dar certo" (p. 84), um discurso de verdade única no qual a reflexão desaparece (p. 91). Mas como lidar com essa sobreposição entre condições precárias de trabalho e abertura para a criação e invenção de práticas, conduzindo a uma vivência de sobrecarga por parte do trabalhador, por meio das considerações foucaultianas acerca da ética, no sentido de uma prática reflexiva da liberdade e uma estética da existência? Podemos nos perguntar, pelo menos, em que medida novos espaços de problematização, além dos sindicatos e associação de classe, tal com é o caso da supervisão institucional, também não instalam regimes de verdade, não é mesmo?

Enfim, talvez o maior mérito do livro esteja na abordagem foucaultiana que põe em ação a idéia de "jogos de verdade”, pois ela permite notar a rede enunciativa 
presente nas leis e portarias governamentais, como também nos relatórios das conferências nacionais de saúde. Esse livro nos permite perceber que tais documentos não são apenas normas a serem conferidas no cotidiano dos serviços, mas também um produto de lutas pelo estatuto de verdade universal. Assim, grande parte do material cotidiano dos gestores, qual seja, os documentos, pode receber um tratamento diverso do exame das etapas "planejamento - implantação - fiscalização - avaliação" de ações, normalmente voltado para conferir se "o que deve ser feito está sendo cumprido".

A abordagem adotada pela autora permite tomar os documentos como produto da gênese de discursos, hegemônicos ou não, por vezes com ou às vezes sem a participação da população e, principalmente, dos trabalhadores, na formulação das políticas públicas. 